\title{
SiC epitaxy growth using chloride-based CVD
}

\author{
Anne Henry, Stefano Leone, Franziska Beyer, Henrik Pedersen, Olle Kordina, \\ Sven Andersson and Erik Janzén
}

\section{Linköping University Post Print}

N.B.: When citing this work, cite the original article.

Original Publication:

Anne Henry, Stefano Leone, Franziska Beyer, Henrik Pedersen, Olle Kordina, Sven Andersson and Erik Janzén, SiC epitaxy growth using chloride-based CVD, 2012, Physica. B, Condensed matter, (407), 10, 1467-1471.

http://dx.doi.org/10.1016/j.physb.2011.09.063

Copyright: Elsevier

http://www.elsevier.com/

Postprint available at: Linköping University Electronic Press

http://urn.kb.se/resolve?urn=urn:nbn:se:liu:diva-77522 


\title{
SiC epitaxy growth using chloride-based CVD
}

\author{
$\underline{\text { Anne Henry }^{1, a}}$, Stefano Leone $e^{1, b}$, Franziska C. Beyer ${ }^{1, \mathrm{c}}$, Henrik Pedersen ${ }^{1, \mathrm{~d}}$ Olof Kordina ${ }^{1, \mathrm{e}}$
} Sven Andersson ${ }^{1, \mathrm{f}}$ and Erik Janzén ${ }^{1, \mathrm{~g}}$

${ }^{1}$ Department of Physics, Chemistry and Biology, Linköping University, SE-581 83

Linköping, Sweden

Corresponding author e-mail address: a) anhen@ifm.liu.se, Tel: +4613282414,

Fax: +4613142337

b) leone@ifm.liu.se,c)fbeyer@ifm.liu.se,d)henke@ifm.liu.se,e) olkor@ifm.liu.se,

f) svean@ifm.liu.se, g) erija@ifm.liu.se

\section{Abstract}

The growth of thick epitaxial $\mathrm{SiC}$ layers needed for high-voltage, high-power devices is investigated with the chloride-based chemical vapor deposition. High growth rates exceeding $100 \mu \mathrm{m} / \mathrm{h}$ can be obtained, however to obtain device quality epilayers adjustments of the process parameters should be carried out appropriately for the chemistry used. Two different chemistry approaches are compared: addition of hydrogen chloride to the standard precursors or using methyltrichlorosilane, a molecule that contains silicon, carbon and chlorine. Optical and electrical techniques are used to characterize the layers.

\section{Keywords}

Silicon carbide, chloride, epitaxy, doping, PL, DLTS

\section{Introduction}

Silicon carbide is a promising candidate to meet the challenging demands for high temperature, high power and/or high frequency electronic devices on account of its excellent properties such as the high breakdown electric field strength, high saturated electron drift velocity and high thermal conductivity. This provides $\mathrm{SiC}$ technology advantages over mainly Si technology in terms of lower on-state and switching losses at the voltage and current rating of the device. $\mathrm{SiC}$ based power electronics drastically reduce the power losses 
in all power applications involving frequency control or inverter circuitry at voltages in excess of $600 \mathrm{~V}$. The higher frequency, smaller dimensions, less cooling requirements and greater efficiency obtained with $\mathrm{SiC}$ power electronics grant lighter, less expensive, and more efficient systems for any application. Today, all SiC device structures require an epitaxial layer to be grown on top of the wafer. The state-of-the-art epilayers are preferably grown by Hot-Wall Chemical Vapor Deposition (HWCVD) using silane $\left(\mathrm{SiH}_{4}\right)$ and a light hydrocarbon, such as propane $\left(\mathrm{C}_{3} \mathrm{H}_{8}\right)$ or ethylene $\left(\mathrm{C}_{2} \mathrm{H}_{4}\right)$, as precursors heavily diluted in hydrogen [1]. Typical growth rates are about $5-10 \mu \mathrm{m} / \mathrm{h}$ which give long growth times for the thick epitaxial layers that are required for high voltage devices. As an example a $10 \mathrm{kV}$ blocking device would require about $100 \mu \mathrm{m}$ thick low doped (about $10^{14} \mathrm{~cm}^{-3}$ ) drift layer. The main problem when trying to achieve higher growth rates by increasing the precursor flows is the formation of aggregates in the gas phase; these aggregates are mainly silicon droplets and their formation results in a saturation of the growth rate. When the droplets come in contact with the epilayer surface they create very large defects on the surface making the epilayer unusable. To overcome this problem, high temperature [2] as well as low pressure processes [3] have been developed where the droplets are either dissolved by the high temperature or transported out of the susceptor by the higher gas flow rate.

An approach to solve the issue with the droplets is reached through the addition of atoms that binds stronger to silicon than silicon itself and thus impedes the formation of the droplets. An appropriate candidate is of course chlorine since it forms strong bonds to silicon and chlorinated compounds of high purity can be purchased as they are often used for the $\mathrm{Si}$ epitaxy. Chloride-based epitaxy has thus merged as a promising way for the growth of thick SiC epilayers since growth rates in excess of $100 \mu \mathrm{m} / \mathrm{h}$ have been reported [4-6]. The addition of chlorine to the gas mixture can be done in different ways: adding hydrogen chloride $(\mathrm{HCl})$ to the standard precursors; using a chlorinated silicon or carbon precursor; Or through the use of a single precursor containing silicon, carbon and chlorine such as methyltrichlorosilane-MTS $\left(\mathrm{CH}_{3} \mathrm{SiCl}_{3}\right)$. We are presenting results using the $\mathrm{HCl}$ $\left(\mathrm{HCl}+\mathrm{SiH}_{4}+\mathrm{C}_{2} \mathrm{H}_{4}\right)$ and the MTS approaches. The morphology of the epilayer is investigated by microscopy and optical and electrical techniques are used to further characterize the layers.

\section{Experimental methods}

Epitaxial layers were grown in a horizontal HWCVD reactor [7] at a typical temperature of $1570{ }^{\circ} \mathrm{C}$. The graphite susceptor, which is heated by RF induction, is coated with $\mathrm{SiC}$ to 
prevent impurities and additional hydrocarbons to be released from the graphite during the growth. The degradation of the coating over time through etching at hot spots is impacting the run-to-run reproducibility. For long growth times, required for thick epilayers, the susceptor may change its properties within the run, which can be a severe issue when using the standard chemistry (without chlorine) since the growth rates are so low. The substrates are held on a $\mathrm{SiC}$ coated plate placed almost horizontally a few $\mathrm{mm}$ above the bottom of the susceptor. No substrate rotation is used in these experiments. Growth is typically performed at a reduced pressure of 200 mbar. A Pd-Ag membrane hydrogen purifier provides highpurity $\mathrm{H}_{2}$ carrier gas. Silane (100\%), ethylene (100\%) or MTS are used as precursors, because to the liquid state of MTS at room temperature is carrier gas bubbling used to transport MTS into the gas mixture. Different conditions may be used during the temperature ramp-up: A carbon-rich ambient has been proposed as preferable for the growth on $8^{\circ}$ offaxis substrate [8] when $\mathrm{HCl}$ is not available, however small amounts of $\mathrm{HCl}$ gas during the temperature ramp-up has also being suggested to improve the morphology of the grown layer [9]. N-type doping is achieved by adding small amounts of nitrogen gas.

The morphology of the epilayers was studied through an optical microscope with Normaski differential contrast (NDIC). The thickness of the layers was determined either from a cleaved face of the sample or from reflectance technique [10]. In the low temperature photoluminescence (LTPL) experiments the sample was excited by the $244 \mathrm{~nm} \mathrm{Ar}^{+}$laser line and the luminescence was dispersed by a single grating monochromator on which a UV sensitive CCD camera was mounted to rapidly detect the PL spectra. The samples were immersed in a He bath cryostat and kept at $2 \mathrm{~K}$.

For electrical measurements, Schottky contacts using Nickel or semi-transparent gold contacts were thermally evaporated on the samples with a thickness of approximately $600 \AA$ and $130 \AA$, respectively. The former were used for Deep Level Transient Spectroscopy (DLTS) whereas the latter for Minority Carrier Transient Spectroscopy (MCTS). Silver paint served as ohmic contact covering the backside of the highly doped n-type substrates. For capacitance-voltage (CV) a HP4284 LCR meter operating at a frequency of $1 \mathrm{MHz}$ was used to determinate the net carrier concentration at room temperature. DLTS spectra were taken from 85 to $700 \mathrm{~K}$ by applying a reverse bias of $10 \mathrm{~V}$ followed by a $10 \mathrm{~ms}$ long filling pulse with height of $10 \mathrm{~V}$. MCTS measurements were made from 85 to $350 \mathrm{~K}$ under a constant reversed bias of $10 \mathrm{~V}$ and $200 \mathrm{~ms}$ long laser pulse. The UV lines (351-355 nm) of an Ar ion laser were used as excitation pulse. In both cases transients were acquired during $500 \mathrm{~ms}$. 
The transients were evaluated using lock-in amplifier simulation in the time range 6.6 to 211 ms.

Secondary ion mass spectrometry (SIMS) has been performed on a few samples to determine the concentration of impurities [11]

\section{Results and discussion.}

\subsection{Growth results, growth rate and morphology}

Using both approaches the growth rate was found to increase proportionally with the $\mathrm{Si} / \mathrm{H}_{2}$ ratio in the gas phase. However the MTS approach was found to be more efficient: typically to achieve $100 \mu \mathrm{m} / \mathrm{h}$ using the $\mathrm{HCl}$ process a $\mathrm{Si} / \mathrm{H}_{2}$ ratio of $0.6 \%$ was needed whereas a ratio of $0.25 \%$ was used for the MTS process [12]. In the previous study no gas liner was used to direct the gas straight into the susceptor in laminar flow conditions; this has been added in the present study together with a redesign of the susceptor. With a ratio of $\mathrm{Si} / \mathrm{H}_{2}=0.15 \%$, a growth rate of $70 \mu \mathrm{m} / \mathrm{h}$ and $60 \mu \mathrm{m} / \mathrm{h}$ can now be achieved with the MTS- and HCl-process, respectively. These results are illustrated in Fig.1 where the thicknesses (Fig. 1a) and the net doping concentration (Fig. 1b) of the epilayers are plotted along the flow direction for both processes. Those layers were grown with the two different processes keeping all the other growth parameters constant such as temperature $\left(1570{ }^{\circ} \mathrm{C}\right)$, pressure $(200 \mathrm{mbar}), \mathrm{C} / \mathrm{Si}=1$, $\mathrm{Si} / \mathrm{H}_{2}=0.15 \%$ and $\mathrm{Si} / \mathrm{Cl}=3$ ratios. The MTS process is still the more efficient process; however the discrepancy mentioned before between both processes is reduced.

The morphology of the epilayer was also found dependent of the used chemistry. Fig.2.a and $b$ illustrates the morphology observed from these two epilayers grown with the MTS and $\mathrm{HCl}$ approach, respectively. The focus on both pictures is on a typical observed defect, which is the well known epi-defect called "carrot". With the MTS approach the density of this type of defects was found to be about $40 \mathrm{~cm}^{-2}$ whereas it increased to $120 \mathrm{~cm}^{-2}$ with the $\mathrm{HCl}$ approach. However changing the ambient during the temperature ramp-up from $\mathrm{C}$ rich conditions to an $\mathrm{HCl}$ ambient (typically $0.04 \%$ of the total gas flow) the carrot density was found to decrease to less than $1 \mathrm{~cm}^{-2}$ and $25 \mathrm{~cm}^{-2}$ for the MTS and $\mathrm{HCl}$ approaches, respectively. Carrot defects have been shown to appear in many different shapes and structures [13], where two of them are shown in Fig.2. The origin of the defect can also vary: most commonly, they are formed at the epilayer/substrate interface where they are pinned to a basal plane dislocation or threading screw dislocation in the substrate, however the formation mechanism is still not understood. 
Both approaches were used to grow epilayers with the following specifications: $12 \mu \mathrm{m}$ thick and $10^{16} \mathrm{~cm}^{-3} \mathrm{n}$-type doping. Results from these runs along the flow direction for 20 $\mathrm{mm}$ long samples are depicted in Fig.3. The $\mathrm{Si} / \mathrm{H}_{2}$ ratio was kept at $0.15 \%$. A small amount of nitrogen gas was added to the gas phase to obtain the correct doping. To compensate for the depletion observed in Fig.1.a. a slight adjustment of the SiC coated plate supporting the sample was made. This adjustment was kept for the remaining experiments. The layer grown using the MTS approach resulted in an almost constant thickness along the flow direction whereas the depletion effect was still apparent for the layer grown with the $\mathrm{HCl}$ process. In the case of the $\mathrm{HCl}$-process some parameters had to be optimized compared to the MTS process in order to obtain a mirror-like surface free of epitaxial defects, such as carrots, etch pits, open core dislocations or silicon aggregates on the surface. With MTS the C/Si and $\mathrm{Cl} / \mathrm{Si}$ ratio are simply derived as a consequence of the use of the single molecule without any addition of other species, resulting in a $\mathrm{C} / \mathrm{Si}=1$ and a $\mathrm{Cl} / \mathrm{Si}=3$. With the $\mathrm{HCl}$ process the same conditions could not be used because a very high density of carrots defects and tiny holes related to silicon aggregates were found on the epilayer surface. A lower content of carbon and increased amount of $\mathrm{HCl}$ were required to obtain a surface comparable to the one obtained with pure MTS. The $\mathrm{C} / \mathrm{Si}$ ratio was consequently reduced to 0.93 and the $\mathrm{Cl} / \mathrm{Si}$ ratio increased to 4.

\subsection{Electrical characterization}

When epitaxial growth is performed on Si face material and using the standard chemistry, the net carrier concentration is known to decrease when the growth rate increases, and when the $\mathrm{C} / \mathrm{Si}$ ratio increases [14]. This is also true for the chloride based epitaxy. Fig.1b shows the net carrier concentration along the flow direction for the both undoped layers grown using both chemistries and for which the growth rate was shown in Fig.1a. For both samples the net carrier concentration is found to increase when the growth rate decreases. However we expect to see a lower net carrier concentration for the MTS process, which gives higher growth rate than the $\mathrm{HCl}$ process. This is not observed. In fact a difference of one order of magnitude is seen with the highest doping for the MTS process. Very low back-ground net carrier concentration in the low $10^{14} \mathrm{~cm}^{-3}$ can be achieved for the $\mathrm{HCl}$ process as shown in Fig.1b. However, typically a growth rate close to $100 \mu \mathrm{m} / \mathrm{h}$ for the MTS approach is needed to obtain a low $10^{14} \mathrm{~cm}^{-3}$ net carrier concentration. Furthermore, the back-ground conductivity of the grown $4 \mathrm{H}-\mathrm{SiC}$ epilayer was found to switch from n-type to p-type when the growth rate was increased further to more than $100 \mu \mathrm{m} / \mathrm{h}$ using either of the gas 
chemistries. This turning point depends on the chemistry used. It is also slightly dependent of the other growth parameters such as $\mathrm{C} / \mathrm{Si}, \mathrm{Cl} / \mathrm{Si}$ ratio and /or temperature.

In order to obtain $10^{16} \mathrm{~cm}^{-3}$ n-type doping $\mathrm{N}_{2}$ gas was introduced. $\mathrm{A} \mathrm{N}_{2} / \mathrm{H}_{2}$ ratio of $0.88 \%$ was needed for the MTS process whereas the $\mathrm{N}_{2} / \mathrm{H}_{2}$ had to be increased to $2 \%$ for the $\mathrm{HCl}$ process on account of its intrinsically lower background doping. The doping uniformity of the layers was, as expected, related to the uniformity of the epilayer thickness. Numerical modeling on the two approaches also indicate that a single chlorinated precursors, such as MTS, should lead to a more uniform C/Si ratio along the susceptor coordinates [15] resulting in a more uniform doping concentration as evidenced in this work.

The fact that MTS process gives a higher net carrier concentration could be due to the effective C/Si ratio is lower when the MTS approach is used (more Si reaches the surface) but it could also be due to the purity of the precursor.

DLTS experiments were carried out to evaluate the electrical properties of the epilayers. The results given here are for either unintentionally doped but n-type or intentionally nitrogen low doped epilayers with carrier concentration typically in the $10^{15} \mathrm{~cm}^{-3}$. Table I gives a summary of these data. Both the MTS and the $\mathrm{HCl}$ approaches give similar results. The DLTS spectra revealed the presence of the well-known $Z_{1 / 2}$ and EH6/7 centers (See Fig. 4.a) with an energy level of $E_{C}-0.67 \mathrm{eV}$ and $E_{C}-1.57 \mathrm{eV}$, respectively. Their capture cross sections as evaluated from the Arrhenius plot of the emission rate were $1 \times 10^{-14} \mathrm{~cm}^{2}$ and $5 \times 10^{14} \mathrm{~cm}^{2}$, respectively. Their defect concentrations which were in the $10^{13} \mathrm{~cm}^{-3}$ range were decreased when both the $\mathrm{C} / \mathrm{Si}$ and $\mathrm{Cl} / \mathrm{Si}$ are increased [15]. For epilayers grown with a very high growth rate and which are intentionally n-doped, additional peaks are observed. The peak detected at low temperature has an activation energy of $\mathrm{Ea}=\mathrm{Ec}-0.18 \mathrm{eV}$ and a capture cross section of $\sigma=4 \times 10^{-13} \mathrm{~cm}^{2}$. The peak observed as a shoulder to the EH6/7 center toward the low temperature side has an activation energy of $\mathrm{Ea}=\mathrm{E}_{\mathrm{C}}-1.40 \mathrm{eV}$ and a capture cross section of $\sigma=1 \times 10^{-13} \mathrm{~cm}^{2}$. Those peaks were first believed to be associated with Ti and a carbon related defect [15]. However, recent investigations of tungsten incorporation in various SiC polytypes [16] suggest that both defect levels are associated with tungsten. Typical doping concentrations extracted form the DLTS are estimated to be in the low $10^{13}$ $\mathrm{cm}^{-3}$ range.

Using minority carrier transient spectroscopy (MCTS) the $\mathrm{HS}_{1}$ defect, which has been correlated to the $\mathrm{D}_{1}$ LTPL line [17], is observed at Ev $+0.37 \mathrm{eV}$ and has a capture cross section of $1 \times 10^{-13} \mathrm{~cm}^{2}$. The defect concentration of $\mathrm{HS}_{1}$ is about $2 \times 10^{12} \mathrm{~cm}^{-3}$. The shallow and deep boron complexes were observed at concentrations in the low $10^{13} \mathrm{~cm}^{-3}$ range. The 
deep center denoted $\mathrm{D}$ has an energy of $\mathrm{Ev}+0.63 \mathrm{eV}$ and a capture cross section of $\sigma=1 \times 10^{-14} \mathrm{~cm}^{2}$. A splitting of the shallow boron peak denoted B was observed using a fourpoint-correlation window, suggested by Dmowski [18], as shown in Fig.4.b. The associated energy levels are at $\mathrm{Ev}+0.27$ and $\mathrm{Ev}+0.28 \mathrm{eV}$ respectively with capture cross section of $2 \times 10^{-14}$ and $8 \times 10^{-15} \mathrm{~cm}^{2}$, respectively. No additional, unidentified defects were observed.

\subsection{Optical characterization}

The LTPL spectra were dominated by the near band-gap (NBG) emission (shown in Fig.5) and a weak observation of the $\mathrm{D}_{1}$ line. No donor-acceptor pair luminescence was observed in the visible range. When the free-exciton (FE) related lines were the dominant lines in the NBG emission weak Ti related lines could sometimes be observed in this visible range. The LTPL spectra of three different samples shown in Fig.5, contain several lines related to the recombination of excitons bound to the two nitrogen donors and/or to the recombination of FE phonon replicas. Since $\mathrm{SiC}$ has an indirect bandgap, the FE is only observed as a recombination involving various phonon replicas. The dominant is labeled $\mathrm{I}_{76}$, where the subscript 76 denotes the energy of the assisting phonon (in meV). 24 different phonon replicas are expected, however due to the polarization selection rule only 12 lines can be observed with the geometry used during the PL experiments. The no-phonon bound-exciton (BE) lines of $4 \mathrm{H}-\mathrm{SiC}\left(\mathrm{P}_{0}\right.$ for nitrogen at the hexagonal site and $\mathrm{Q}_{0}$ at the quasi-cubic site) are also observed together with their phonon replicas, which are labeled in a similar way as the $\mathrm{FE}$ (e.g. $\mathrm{P}_{76}$ ). At very low doping concentrations the FE related lines dominate the PL spectrum as demonstrated in Fig.5c. The FE related lines will decrease when the doping increases and the determination of the nitrogen concentration can be determined from the relative intensity of the $\mathrm{BE}$ and $\mathrm{FE}$ lines [19]. The nitrogen concentration is plotted in Fig.1.b along the flow direction for the epilayers grown with the MTS and $\mathrm{HCl}$ approaches. The data extracted from the LTPL spectra when N-BE lines are visualized are confirmed by the CV measurements.

For samples grown at very high growth rate as such as $210 \mu \mathrm{m} / \mathrm{h}$ (see Fig.5c) the LTPL spectrum is completely dominated by the FE lines and the N-BE lines are extremely weak. In addition hydrogen related lines (labeled $\mathrm{H}_{1}$ and $\mathrm{H}_{2}$ ) are observed in the LTPL spectra, which are well recognized by their typical behavior: their intensity decreases with excitation time together with the observation and increase of specific bond-stretching vibration modes at lower energy [20]. The boron bound-exciton has never been observed in $\mathrm{SiC}$; however it has been predicted that the incorporation of boron, which should occupy the Si-site to be a 
shallow acceptor, is only possible in combination with the presence of hydrogen [21]. The LTPL spectra of p-type boron doped samples lend substance to this prediction as the hydrogen related lines in the NBG emission range [22] can be clearly visible.

\section{Discussion}

The two chemistries used in this study lead to different results and dissimilar process conditions ( $\mathrm{C} / \mathrm{Si}$ - and $\mathrm{Cl} / \mathrm{Si}$-ratios) were required to achieve the deposition of smooth epitaxial layers. Comparing the morphology and the nitrogen incorporation efficiency, the $\mathrm{HCl}$-process seems to have a higher effective $\mathrm{C} / \mathrm{Si}$ ratio on the growing surface compared to MTS when the same process conditions were adopted. In fact the higher density of carrot defects and lower n-type incorporation efficiency when using the $\mathrm{HCl}$ process give evidence of a greater availability of carbon atoms at the surface compared to the MTS process used under similar conditions. This can be explained by the fact that with MTS the main intermediate formed in the gas phase is $\mathrm{SiCl}_{2}$ [14] which is very effective in bringing silicon atoms to the surface. This is not the case with the $\mathrm{SiH}_{4}+\mathrm{C}_{2} \mathrm{H}_{4}+\mathrm{HCl}$ process where not only $\mathrm{SiCl}_{2}$ but also $\mathrm{SiHCl}$ is abundantly formed. Furthermore, by using the $\mathrm{SiH}_{4}+\mathrm{HCl}$ chemistry is the chemical path to form $\mathrm{SiCl}_{2}$ much more complicated; four $\mathrm{Si}-\mathrm{H}$ bonds must be broken and to $\mathrm{Si}-\mathrm{Cl}$ bonds must be formed. The chemical path to form $\mathrm{SiCl}_{2}$ from MTS just involves breaking of one $\mathrm{Si}-\mathrm{Cl}$ and one $\mathrm{Si}-\mathrm{C}$ bond. The lower efficiency of the $\mathrm{SiHCl}$ specie compared to that of the $\mathrm{SiCl}_{2}$ specie give rise to a lower amount of silicon species reaching the surface which in turn results in a higher $\mathrm{C} / \mathrm{Si}$ ratio. The higher growth rate achieved when using MTS lend further credence to the above statement that a higher amount of $\mathrm{SiCl}_{2}$ results in a higher growth rate.

Another relevant phenomenon is the switch of background conductivity from $n$ - to p-type when the growth rate is increased, about $100 \mu \mathrm{m} / \mathrm{h}$ in case of MTS. This could also be explained in terms of the effective C/Si ratio. Previous results from another group [5] showed that when the $\mathrm{HCl}$-process was used, an increase of the growth rate through the introduction of a higher amount of precursors has to be accompanied with a decrease of the C/Si ratio in order to prevent morphology degradation of the epilayer such as higher carrot defect density or even polycrystalline inclusions. These results indicate that when the growth rate is pushed higher, the effective $\mathrm{C} / \mathrm{Si}$ ratio becomes higher too. The same is probably applicable to our results, although the evidence is shown by the background doping concentration. When the effective $\mathrm{C} / \mathrm{Si}$ ratio gets higher due to higher growth rates, the n-type dopant incorporation is hampered, and any p-type dopant impurities existing in the system is easily incorporated. 
The epilayers grown at a very high growth rate with both approaches were found to contain boron, as determined by SIMS analysis. For the epilayer grown at $210 \mu \mathrm{m} / \mathrm{h}$ and for which the LTPL spectrum is shown in Fig.5c, SIMS analysis register a boron concentration of $8 \times 10^{15} \mathrm{~cm}^{-3}$. Boron is present in the system in parts such as quartz and graphite and it could be incorporated when the effective $\mathrm{C} / \mathrm{Si}$ ratio becomes too high. The SIMS measurements could also detect trace amounts of metal impurities such as iron and tungsten (in the low $10^{13}$ $\mathrm{cm}^{-3}$ range).

\section{Conclusions}

The chloride-based CVD process has been described in details as a feasible process to grow high quality epitaxial layers at high growth rates.

A process based on the single molecule MTS has been shown to lead to higher growth rate and improved thickness and doping uniformity compared to a process based on the addition of $\mathrm{HCl}$ to the standard precursors. In the latter case more carbon rich conditions are obtained even when the same process conditions as those obtained from MTS are used. A lower C/Si ratio was needed to obtain a defect-free epilayer when the $\mathrm{HCl}$ chemistry was used. Using this chemistry it could also be noted that a more severe depletion of the precursors and a different gas phase chemistry made the thickness and doping uniformity much worse.

A drawback of the MTS chemistry is that for growth rates exceeding $100 \mu \mathrm{m} / \mathrm{h}$ the effective $\mathrm{C} / \mathrm{Si}$ ratio becomes too high, favoring the incorporation of $\mathrm{p}$-type dopant and metallic impurities in the epilayers.

\section{Acknowledgement}

The Swedish Energy Agency and the Swedish Research Council are gratefully acknowledged for financial support as well as the Africa/Swedish Research Cooperation Program.

\section{References}

[1] O. Kordina, C. Hallin, A. Henry, J. P. Bergman, I. Ivanov, A. Ellison, N. T. Son, and E. Janzén; Phys. Stat. Sol- B 202, (1997) 321.

[2] A. Ellison, J. Zhang, A. Henry, E. Janzén, Journal of Crystal Growth 236 (2002) 225

[3] M. Ito, L. Storasta, H. Tsuchida, Applied Physics Express 1 (2008) 015001

[4] H. Pedersen, S. Leone, A. Henry, F.C. Beyer, V. Darakchieva, E. Janzén; J. Cryst. Growth 307 (2007) 334. 
[5] F. La Via, G. Galvagno, G. Foti, M. Mauceri, S. Leone, G. Pistone, G. Abbondanza, A. Veneroni, M. Mazi, G. L. Valente, D. Crippa, Chemical Vapor Deposition 12 (2006) 509.

[6] S. Leone, F. C. Beyer, H. Pedersen, O. Kordina, A. Henry, E. Janzén, Crystal Growth \& Design 10 (2010) 5334-5340.

[7] A. Henry, J. ul Hassan, J.P. Bergman, C. Hallin and E. Janzén; Chemical Vapor Deposition 12 (2006) 475-482.

[8] C. Hallin, F. Owman, P. Mårtensson, A. Ellison, A. Konstantinov, O. Kordina, E. Janzén, J. Crystal Growth 181 (1997) 241.

[9] A. Burk, L. B. Rowland, Applied Physics Letters, 68 (1996) 382-385

[10] M. F. MacMillan, A. Henry, and E. Janzén; J. Electron. Mater 27 (1998) 300-304.

[11] E.A.G., Evans Analytical Group, Sunnyvale, California, USA.

[12] H. Pedersen, S. Leone, A. Henry, A. Lundskog and E. Janzén, phys. Sts. Sol. (RRL) 6 (2008) 278-280.

[13] J. Hassan, A. Henry, P.J. McNally and J.P. Bergman, J. Cryst. Growth, 313 (2010) $1828-1837$

[14] U. Forsberg, Ö. Danielsson, A. Henry, M.K. Linnarsson, and E. Janzén; J. Cryst. Growth $\underline{236}(2002) 101$

[15] S. Nishizawa, J. Cryst. Growth, 311 (2009) 871-874.

[15] F.C. Beyer, H. Pedersen, A. Henry, E. Janzén, Materials Science Forum 617-617 (2009) 373-376.

[16] F. C. Beyer, C. G. Hemmingsson, A. Gällström, S. Leone, H. Pedersen, A. Henry, and E. Janzén, Appl. Phys. Lett. 98 (2011) 152104-152106.

[17] L. Storasta, F.H.C. Carlsson, S.G. Sridhara, J.P. Bergman, A. Henry, T. Egilsson, A. Hallén, and E. Janzén; Appl. Phys. Lett. 78, (2001) 46-49.

[18] K. Dmowsli, Solid-State Electronics 38 (1995) 1051-1057.

[19] I.G. Ivanov, C. Hallin, A. Henry, O. Kordina and E. Janzén; J. Appl. Phys. 80 (1996) 3504-3508.

[20] W.J. Choyke and L. Patrick, Phys. Rev. Lett. 19 (1972) 355-358.

[21] B. Aradi, P. Deák, N. T. Son, E. Janzén, W. J. Choyke, and R. P. Devaty; Appl. Phys. Lett. 79 (2001) 2746-2748.

[22] D. J. Larkin, S. G. Sridhara, R. P. Devaty and W. J. Choyke, Journal of Electronic Materials Volume 24, (1995) 289-294. 
Table I: Properties levels observed by DLTS and MTS Ea and _ $\sigma$ are obtained from Arrhenius plots of the emission rate and $\mathrm{N}_{\mathrm{T}}$ from the peak amplitudes (the range denoted values obtained from various measurements and samples)

\begin{tabular}{|l|l|l|l|}
\hline Defect & Ea $(\mathrm{eV})$ & $\sigma\left(\mathrm{cm}^{2}\right)$ & $\mathrm{N}_{\mathrm{T}}\left(\mathrm{cm}^{-3}\right)$ \\
\hline $\mathrm{Z}_{1 / 2}$ & $\mathrm{Ec}-0.67$ & $1 \times 10^{-14}$ & $1-10 \times 10^{13}$ \\
\hline $\mathrm{EH}_{6} / 7$ & $\mathrm{Ec}-1.57$ & $5 \times 10^{-14}$ & $1-10 \times 10^{13}$ \\
\hline $\mathrm{W}_{1}$ & $\mathrm{Ec}-0.18$ & $4 \times 10^{-13}$ & $2 \times 10^{13}$ \\
\hline $\mathrm{W}_{2}$ & $\mathrm{Ec}-1.40$ & $1 \times 10^{-13}$ & $2 \times 10^{13}$ \\
\hline $\mathrm{Ti}$ & $\mathrm{Ec}-0.17$ & $6 \times 10^{-14}$ & $2-7 \times 10^{12}$ \\
\hline $\mathrm{B}_{1}$ & Ev+0.27 & $2 \times 10^{-14}$ & $1 \times 10^{13}$ \\
\hline $\mathrm{B}_{2}$ & Ev+0.28 & $8 \times 10^{-15}$ & $1 \times 10^{13}$ \\
\hline $\mathrm{HS}_{1}$ & Ev+0.37 & $1 \times 10^{-13}$ & $2 \times 10^{12}$ \\
\hline $\mathrm{D}$ & Ev+0.63 & $1 \times 10^{-14}$ & $2 \times 10^{13}$ \\
\hline
\end{tabular}




\section{Figure Caption}

Fig.1.a) Growth rate and b) net carrier concentration as extracted from PL measurements on the same samples along the flow direction for the both processes (MTS and $\mathrm{HCl}$ ) when the growth was done at $1570{ }^{\circ} \mathrm{C}, 200$ mbar, for one hour and with $\mathrm{C} / \mathrm{Si}=1, \mathrm{Si} / \mathrm{H}_{2}=0.15 \%$ and $\mathrm{Si} / \mathrm{Cl}=3$ ratios.

Fig.2: Typical defects observed on the epilayers grown with a) the MTS and b) the $\mathrm{HCl}$ approach, respectively

Fig.3: Thicknesses and doping concentration of epilayers grown with the MTS and HCl approaches

Figure 4.a) Typical DLTS and MTCS spectra of two layers grown with different growth rates and b) MTCS spectra with four-point-correlation window for the layer grown with the higher growth rate

Fig.5: LTPL recorded at $2 \mathrm{~K}$ using the $244 \mathrm{~nm}$ laser line as excitation for layers growth with a) MTS and b) HCL (same sample than Fig.1) and c) with MTS process achieving a growth rate of $210 \mu \mathrm{m} / \mathrm{h}$ (the sample showed a p-type conductivity and SIMS analysis $8 \times 10^{15} \mathrm{~cm}^{-3}$ boron atoms) 

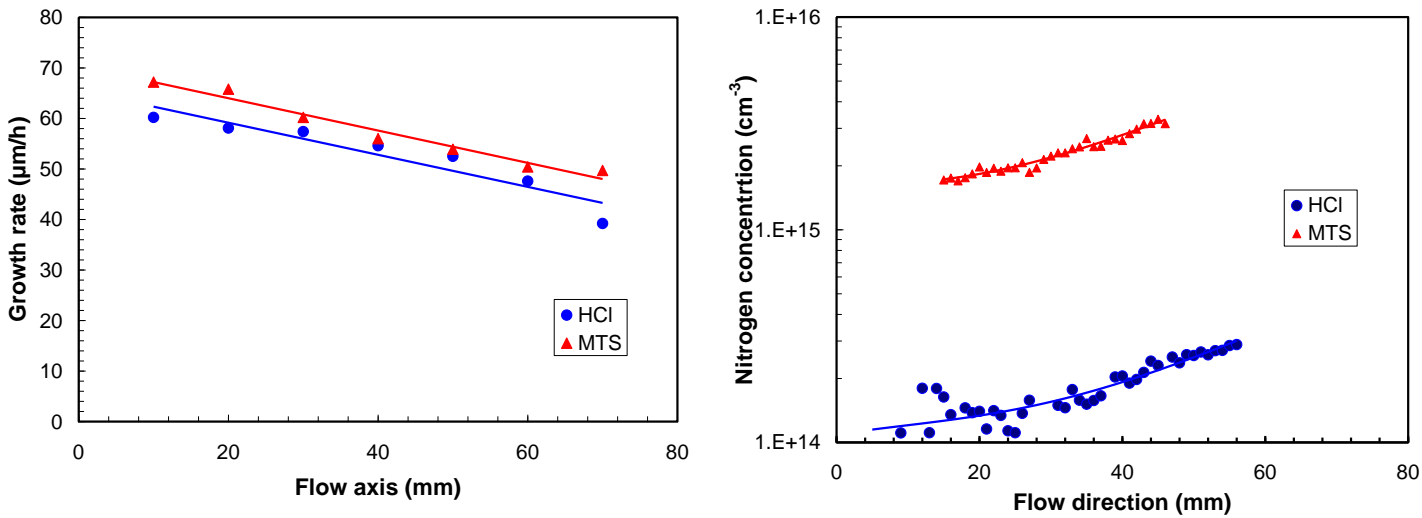

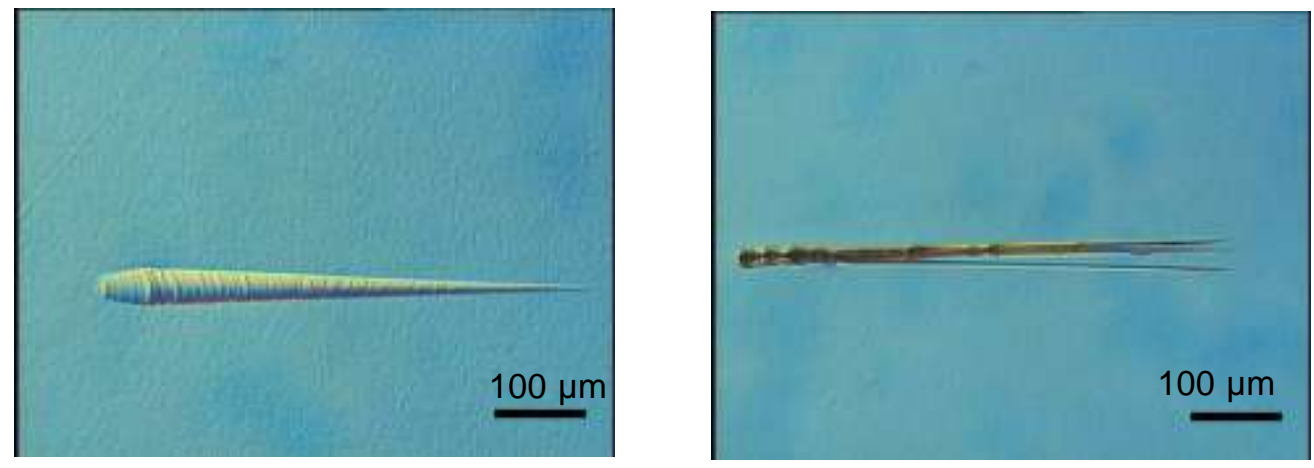


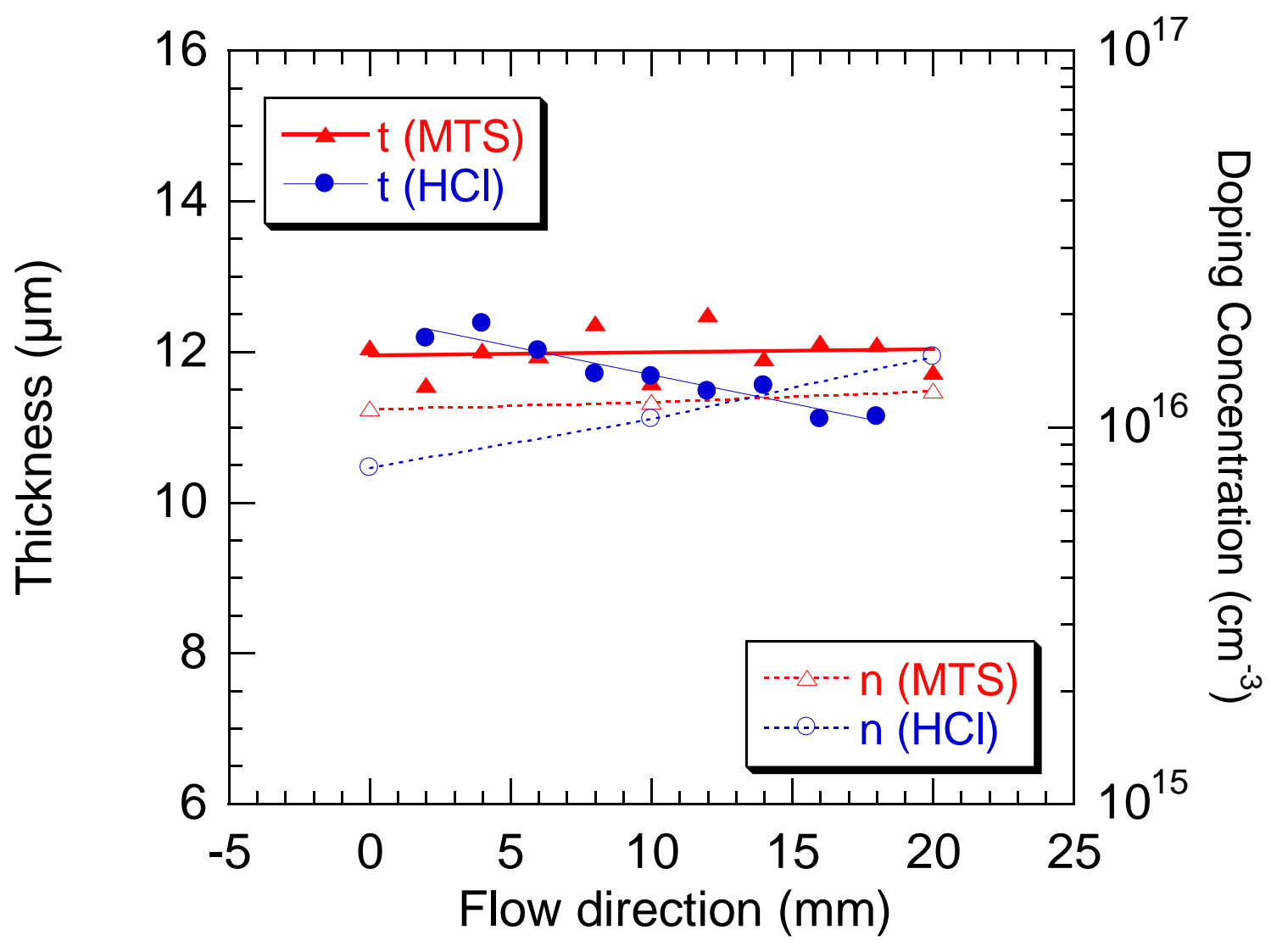


a)

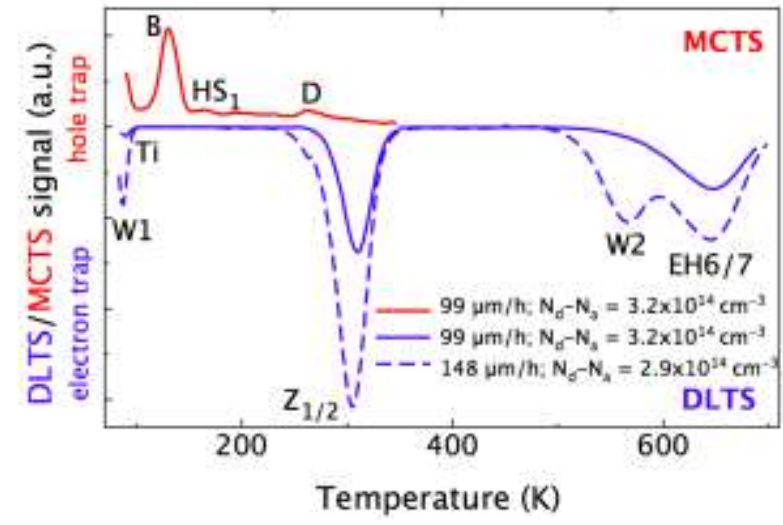

b)

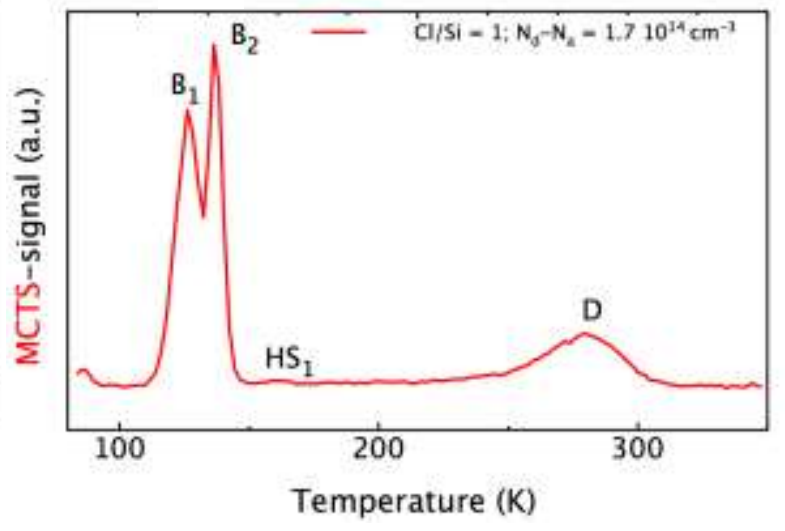




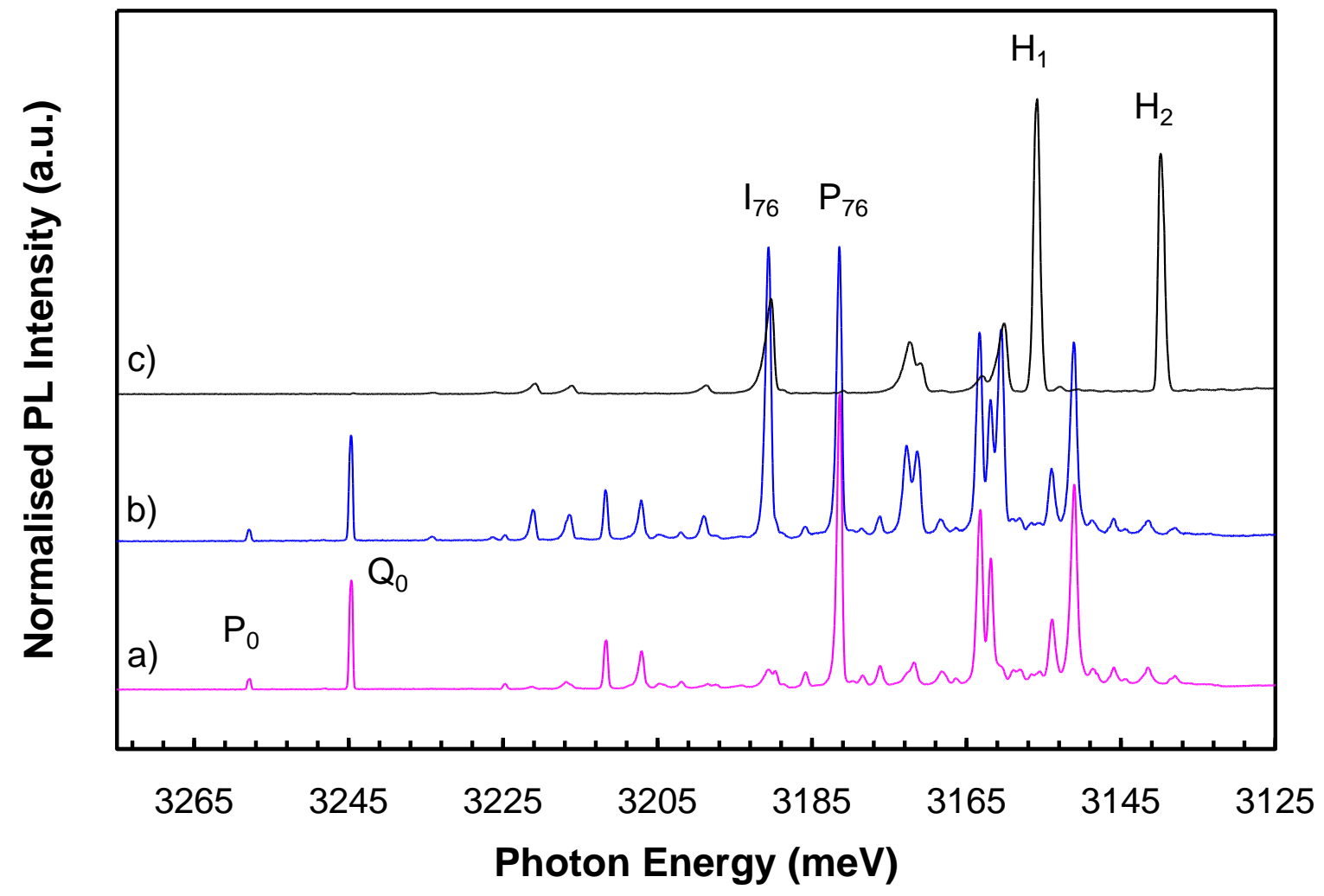

